\title{
Relações entre a educação para o futuro e o ensino do Design na atualidade
}

\author{
Cidaley de Oliveira Moreira, Samantha ${ }^{a}$; Bom Conselho Sales, Rosemary ${ }^{b}$; Barbosa, \\ Paula Glóriac $^{c}$ \& Aguilar, Maria Teresa Paulino ${ }^{d}$. \\ ${ }^{a} \mathrm{PhD}$ candidate at Universidade do Estado de Minas Gerais, Brazil. samanthacidaley@ gmail.com \\ ${ }^{\text {b}} \mathrm{PhD}$ Mechanical Engineering. Universidade Federal de Minas Gerais, Brazil. rosebcs@ gmail.com \\ 'Instituto Federal de Educação, Ciência e Tecnologia de Minas Gerais, Brazil. \\ paula.barbosa@ifmg.edu.br \\ ${ }^{\mathrm{d}}$ Universidade Federal de Minas Gerais, Brazil. teresa@ufmg.br
}

\begin{abstract}
Resumo
O relatório produzido para a Unesco, no final do século passado, preconiza que para superar os desafios de um futuro próximo, o aprendizado, neste século, deverá estar apoiado em quatro pilares fundamentais: aprender a conhecer, aprender a fazer, aprender a viver com os outros e aprender a ser. Para essa nova geração, cujo cotidiano está marcado pelo excesso de informações e diversidade de possibilidades, torna-se imperativo o desenvolvimento de competências múltiplas. Estabelecendo conexão entre ensino e aprendizado, a ação educativa se faz nas relações do homem com o mundo, materializando-se numa série de habilidades e atitudes, que ocasionam mudanças intelectuais, emocionais e sociais nos indivíduos. $O$ processo educativo é o comportamento que mais marca o nosso dia-a-dia e o mais cotidiano dos processos que orientam o nosso agir. O Design, atividade de natureza projetual potencialmente transformador, atua no ajuste da materialidade aos modos e meios de vida dos indivíduos. Dedicado ao projeto de futuros desejáveis, é essencial que o designer aprenda a olhar o mundo, os lugares e as coisas pelo ponto de vista das pessoas que utilizarão produtos, processos e ou serviços projetados por ele. Para que os desafios de projeto sejam identificados adequadamente, o planejamento seja assertivo e a solução inovadora, é necessário que o designer conheça, faça, viva e seja um pouco do outro. É consenso no meio acadêmico que os processos
\end{abstract}


educativos em Design invistam na transdisciplinaridade para o desenvolvimento de visão sistêmica, de modo que o estudante seja capaz de atuar com competência em situações cotidianas ou inusitadas. Entre o ideal e o real, este artigo faz uma reflexão sobre preceitos que norteiam o ensino para o século XXI e orientações que fundamentam os processos educativos em Design na atualidade brasileira, buscando relações entre os dados. Além do estudo apresentado pela Unesco, foram investigadas outras fontes para identificar as abordagens propostas para o futuro do ensino e, mais especialmente, nos cursos de graduação em Design no Brasil. De um modo geral, os resultados evidenciam lacunas a serem preenchidas. Considera-se necessária a revisão dos processos educativos, para que se possa potencializar o conhecimento e a formação dos estudantes de Design para o futuro e, consequentemente, impulsionar sua atuação na promoção da inovação científica, tecnológica e social no presente.

Palavras-Chave: processo educativo, design, ensino superior, inovação.

\begin{abstract}
The UNESCO report, produced at the end of the last century, recommends that to meet a near future challenges, learning in this century should be supported by four pillars: learning to know, learning to do, learning to live with others and learning to be. For this new generation, whose daily life is marked by the information excess and possibilities diversity, it is imperative to develop multiple skills. Establishing a teaching and learning connection, educational action is in man's relations with the world, materializing itself in a number of skills and attitudes that causes intellectual, emotional and social changes in individuals. The educational process is the behavior that marks the most our day-to-day and one of the most common processes that guide our actions. The design, potentially transformative activity of projetual nature, acts in the setting of materiality to the individuals life's ways and means. Dedicated to desirable future project, it is essential that the designer learn to see the world, places and things from the point of view of people who use products, processes or services designed by him. For properly identified design challenges, assertive planning and innovative solution, it is necessary that the designer knows, does, lives, and be a little of the other. It is consensus in academia that Design educative processes must invest in
\end{abstract}


transdisciplinarity to a systemic view development, so that the student will be able to act competently in everyday or unusual situations. Between the ideal and the real, this article reflects about principles that guide the twenty-first century education and the guidelines that support the Design educational processes in Brazil today, searching for relationships between the data. In addition to the study presented by UNESCO, other sources were investigated to identify the approaches proposed to the education future and, more especially, in the brasilian Design undergraduate courses. In general, the results show gaps to be filled. It is considered necessary to review the educational processes, enhancing the knowledge and preparation of Design students to the future and, consequently, boost their role in promoting scientific, technological and social innovation in the present.

Key-words: education process, design, high education, inovation.

\section{A educação para o futuro}

A diversidade e a amplitude das mudanças no contexto da existência humana é uma realidade no cotidiano de grande parte da população, sobretudo a urbana, afetando especialmente o cenário tradicional, que privilegia o pensamento cartesiano e a razão acima da emoção. Em diversas partes do mundo, muitas pessoas se desnorteiam em meio ao excesso de possibilidades e alternativas proporcionadas pelo rápido desenvolvimento da sociedade da informação. O volume de dados disponíveis no sistema global e a relativa facilidade de acesso às redes de contato entre as pessoas determina uma realidade que impacta na percepção de mundo, nas expectativas de vida e nas vivências individuais e coletivas. Nesse contexto, o efêmero apresenta-se como característica marcante nas ações cotidianas, o que provoca, em certa medida, o esvaziamento de atenção e importância aos detalhes que tocam os sentidos e encantam o viver. Diante desse cenário complexo é preciso que as pessoas tenham habilidade para coletar, selecionar, ordenar, gerenciar e utilizar as informações disponíveis, conforme suas necessidades, desejos e possibilidades. Acredita-se que a educação, determinada pelos processos de ensino e aprendizado, seja o caminho mais indicado para a construção de habilidades que facilitem às pessoas lidarem com os limites e as oportunidades dessa realidade.

Ao final da década de 1990, a Organização das Nações Unidas para a Educação, a Ciência e a Cultura (UNESCO) atribuiu ao economista Jacques Delors a coordenação de uma comissão internacional para elaboração de um estudo sobre a educação para o século XXI. 
O trabalho deu origem ao relatório intitulado "Educação um tesouro a descobrir". Considerando a força e a atualidade desse trabalho, ainda hoje serve de referência e orienta diversos planos de ação em instituições de ensino, dos anos iniciais ao ensino superior.

Dentre outras questões que tocam as esferas da vida e do desenvolvimento humano, no citado relatório estão identificadas tensões que, para Jacques Delors e sua equipe, constituem o cerne da problemática do século XXI. Tais tensões se localizam entre ideias que constituem e conformam: o global e o local; o universal e o singular, a tradição e a modernidade; as soluções a curto e a longo prazos; a indispensável competição e o cuidado com a igualdade de oportunidades; o extraordinário desenvolvimento dos conhecimentos e a capacidade de assimilação pelo homem; e enfim, entre o espiritual e o material. Para os autores, é preciso assumir a existência dessas tensões para que seja possível superá-las.

Conhecer melhor o outro e o mundo é uma premissa para superação das tensões, próprias desse nosso século. Diante do cenário que se configura, moldado pelo progresso tecnológico em paralelo à expansão da importância das questões cognitivas e imateriais na produção de bens e serviços, Jacques Delors anuncia que, para a formação da "sociedade de amanhã", é preciso "repensar o lugar ocupado pelo trabalho e seus diferentes estatutos". De acordo com a comissão internacional, para a criação desta nova sociedade, "a imaginação humana deve ser capaz de se adiantar aos avanços tecnológicos", evitando assim, "o aumento do desemprego, a exclusão social, as desigualdades do desenvolvimento". (UNESCO, 1996, p.18)

Como suporte para essa nova mentalidade em construção, Jacques Delors (UNESCO, 1996) indica o processo de educação ao longo da vida. Dispondo de vantagens tais como a flexibilidade, diversidade e acessibilidade no tempo e no espaço, a educação ao longo da vida deve servir ao desenvolvimento do ser humano em sua integridade, o que implica avanços na vida profissional das pessoas, construção contínua de seus saberes e aptidões, assim como da sua capacidade de discernir e de agir. Em paralelo, se faz necessário exercitar valores tais como a compreensão, o auxílio ao próximo e a harmonia nas relações humanas. Para que seja instituído o espírito de um novo tempo, os processos educativos devem ser capazes de auxiliar às pessoas a terem consciência de si e do meio ambiente. Para isso, está recomendado no relatório que a educação para o futuro esteja apoiada em quatro pilares: aprender a conviver, aprender a conhecer, aprender a fazer e aprender a ser.

Conviver não é uma tarefa fácil de se aprender, considerando, especialmente, a complexidade que se estabelece em nosso cotidiano. Aprender a viver junto exige que as pessoas busquem o conhecimento de suas origens, limites e potenciais para que lhes seja possível conhecer histórias, tradições e espiritualidade uns dos outros. (UNESCO, 1996) 
Para que essa tarefa fique mais simples é preciso aprender a conhecer, sufiscientemente, a cultura geral e dominar, profundamente, assuntos específicos. E, no ensejo de conhecer mais e melhor sobre o mundo, as pessoas tendem a desenvolver em si o gosto pelo conhecimento, exercitando, assim, o aprendizado contínuo. (UNESCO, 1996)

O conhecimento progressivo das variáveis da vida e do mundo descortina aos nossos sentidos os desafios a se superar, no exercício de convivência consigo e com os outros. Para facilitar o cumprimento das tarefas nessa trajetória de superação, é preciso que as pessoas aprendam a fazer, ou seja, que saibam dar solução prática às intenções. Com vistas a assertividade na ação, e em resposta à amplitude das demandas na realidade atual, é desejável que as pessoas adquiram competências múltiplas. (UNESCO, 1996)

Para que se consiga fazer a diferença no enfrentamento de situações corriqueiras ou imprevisíveis, no campo profissional, nos ambientes domésticos ou em outros lugares cotidianos, antes de tudo é preciso aprender a ser. Ao aprender a ser, aprendemos a exercitar nossos talentos pessoais, tais como a memória, o raciocínio, a imaginação, a capacidade física, o sentido estético, a facilidade de comunicação, o carisma, entre outros tesouros muitas vezes escondidos pelo desconhecimento ou falta de compreensão da dimensão do potencial de cada um de nós. Aprender a ser relaciona-se à capacidade que as pessoas dispõem para compreender e assumir suas responsabilidades no processo de construção de um destino coletivo. Implica, nesse sentido, o exercício da autonomia e do discernimento, para que haja benefícios à toda humanidade e não apenas a uma parte dela. (UNESCO, 1996)

Às instituições de ensino, nos diversos estágios do desenvolvimento do ser humano, cabe o fomento à educação para o futuro. Especialmente nos países em desenvolvimento, como o Brasil, recomenda-se que nas instituições de ensino superior (IES) sejam desenvolvidas pesquisas teóricas ou aplicadas, em busca de solução aos problemas identificados na realidade local. No contexto das IES desses países, é preciso que sejam propostas novas perspectivas de desenvolvimento para que haja a construção de um futuro melhor à população nas diversas regiões. Para que saiam do ciclo de pobreza e subdesenvolvimento, aos professores do ensino superior cabe a tarefa de formar profissionais necessários ao desenvolvimento sustentável de seus países. (UNESCO, 1996)

Corroborando com as orientações de Jacques Delors e sua equipe, pode-se evocar as idéias defendidas por Edgar Morin (2011). A obra desse autor apresenta os sete saberes necessários à educação do futuro e pode ser compreendida como um convite à reflexão sobre a essência e a origem dos processos de conhecimento, considerando que o indivíduo deve estar preparado para enfrentar os riscos e as ilusões da vida diária. 
Em meio à diversidade cultural e à pluralidade dos indivíduos, na atualidade, deve-se orientar a educação para o desenvolvimento do senso de compreensão e da sensibilidade, com base nos princípios éticos. Envolvendo essencialmente as relações entre indivíduo sociedade - natureza, a educação para o futuro deve ter como foco central a condição humana, considerando que o ser humano é, a um só tempo, físico, biológico, psíquico, cultural, social e histórico. Para o desenvolvimento do ser humano na sua totalidade, há de se incentivar que as diversas disciplinas escolares convirjam para integração de conteúdos, consolidando a construção de um conhecimento transdisciplinar.

Para a assertividade da aplicação desse conhecimento no cotidiano, Edgar Morin (2011) orienta para a necessidade de apreensão dos problemas globais e das realidades locais, no entendimento de que os acontecimentos na localidade interferem na totalidade, e vice versa. A compreensão da relação entre a diversidade e a singularidade, chama à consciência a responsabilidade de cada um de nós para o equilíbrio global, à medida que tudo está interligado.

Nesse processo, o autor nos faz pensar sobre a postura das escolas no presente, que, nos processos educativos, valorizam as certezas geradas pela ciência e ignoram as ambiguidades. Para Morin (2011), a escola no futuro deve educar as pessoas para que sejam capazes de enfrentar os desafios e resolver problemas reais, considerando, para isso, a possibilidade do enfrentamento aos imprevistos.

Afim de promover reformas das mentalidades, a prática da empatia é uma sugestão, considerando que, na tentativa de compreender mais e melhor o outro, acabamos por compreender mais e melhor nossa própria existência.

Nessa relação que orienta a educação para o futuro, a ética assume lugar de destaque. Para que tudo fique bem para todos é necessário tomar consciência de que o ser humano é, ao mesmo tempo, um indivíduo e parte de uma sociedade. Isso implica que os atos praticados por uns afeta aos outros, e tudo o que fazemos ao mundo reflete em nós mesmos.

A complexidade do mundo na atualidade decorre do fato de que tudo está interligado, conformando uma rede. Sabendo que nossas atitudes definem o nosso futuro, é preciso "viabilizar práticas pedagógicas fundamentadas na solidariedade, na ética, na paz e na justiça social" (Morin, 2011, p.13). Para aprender a lidar com essa realidade que se revela aos nossos olhos, à medida que tomamos consciência da amplitude da vida, entendemos a orientação de Edgar Morin (2011, p.13) quando indica ser essencial a criação de espaços "dialógicos, criativos, reflexivos e democráticos". Na possibilidade de constituir uma nova mentalidade, a sala de aula deve se apresentar de outra maneira, não somente no que se refere ao arranjo do mobiliário, mas na ambiência, possibilitando melhor interação entre os estudantes e maior reflexão sobre "as coisas do mundo". 


\section{Diretrizes curriculares e orientações para a formação de designers no Brasil}

A Constituição da República Federativa do Brasil de 1988, em seu artigo 205, determina que a educação - dever da família e do Estado - tenha, por finalidade, o preparo do indivíduo para o mundo do trabalho (qualificação profissional) e para a prática social (exercício da cidadania), por meio do desenvolvimento de aptidões, potencialidades e da personalidade do educando. Para tal, entre outras disposições, confere às universidades autonomia didático-científica, administrativa e de gestão financeira e patrimonial, exigindo que exista indissociabilidade entre ensino, pesquisa e extensão (artigo 207), e determina que seja competência privativa da União legislar sobre as diretrizes e bases da educação nacional (artigo 22, inciso XXIV).

A Lei de Diretrizes e Bases da Educação Brasileira (LDB), Lei n 9.394, de 20 de dezembro de 1996 (Brasil, 1996), determina, no que se refere ao ensino superior (artigo 43), que a educação deve:

I - estimular a criação cultural e o desenvolvimento do espírito científico e do pensamento reflexivo;

II - formar diplomados nas diferentes áreas de conhecimento, aptos para a inserção em setores profissionais e para a participação no desenvolvimento da sociedade brasileira, e colaborar na sua formação contínua;

III - incentivar o trabalho de pesquisa e investigação científica, visando o desenvolvimento da ciência e da tecnologia e da criação e difusão da cultura, e, desse modo, desenvolver o entendimento do homem e do meio em que vive;

IV - promover a divulgação de conhecimentos culturais, científicos e técnicos que constituem patrimônio da humanidade e comunicar o saber através do ensino, de publicações ou de outras formas de comunicação;

$\mathrm{V}$ - suscitar o desejo permanente de aperfeiçoamento cultural e profissional e possibilitar a correspondente concretização, integrando os conhecimentos que vão sendo adquiridos numa estrutura intelectual sistematizadora do conhecimento de cada geração;

VI - estimular o conhecimento dos problemas do mundo presente, em particular os nacionais e regionais, prestar serviços especializados à comunidade e estabelecer com esta uma relação de reciprocidade;

VII - promover a extensão, aberta à participação da população, visando à difusão das conquistas e benefícios resultantes da criação cultural e da pesquisa científica e tecnológica geradas na instituição; 
VIII - atuar em favor da universalização e do aprimoramento da educação básica, mediante a formação e a capacitação de profissionais, a realização de pesquisas pedagógicas e o desenvolvimento de atividades de extensão que aproximem os dois níveis escolares.

Somado aos mencionados deveres da educação de ensino superior no Brasil, o artigo 53 da LDB 9.394/96 (Brasil, 1996) reforçou a autonomia didático-científica das universidades, conferindo-lhes, dentre outras, as atribuições de criar, organizar e extinguir cursos e programas de educação superior, obedecendo às normas gerais da União, e fixar os currículos dos seus cursos e programas, observadas as diretrizes gerais pertinentes. Cabe, neste ponto, mencionar a grande conquista que essa autonomia e consequente liberdade representaram para o ensino superior brasileiro, até então engessado pelas estruturas curriculares mínimas da Lei de Diretrizes e Bases precedente, a LDB 4.024/61 (Brasil, 1961).

Os Currículos Mínimos, direcionados basicamente ao exercício profissional e presos a estruturas rígidas, conduziram a uma formação superior carente de flexibilidade que, na maioria dos casos, não acompanhou as mudanças sociais, tecnológicas e científicas do processo de desenvolvimento da sociedade. Desse estado de coisas resultou uma crescente defasagem dos graduados em relação ao competente desempenho necessário no contexto pós-acadêmico. (Couto, 2008, p.18).

No que se refere ao estabelecimento de diretrizes para elaboração dos cursos e programas de ensino superior, a Lei ${ }^{\circ}$ 9.131, de 24 de novembro de 1995 (Brasil, 1995), artigo $9^{\circ}$, $\S$ $2^{\circ}$, alínea "c", conferiu à Câmara de Educação Superior (CES) do Conselho Nacional de Educação (CNE) a competência para "deliberar sobre as diretrizes curriculares propostas pelo Ministério da Educação e do Desporto, para os cursos de graduação". Com efeito, a CES editou, em 11 de março de 2003, o Parecer no 67 (CNE/CES, 2003a), atual referencial para as diretrizes curriculares dos cursos de graduação no Brasil. Essas diretrizes devem ser respeitadas por todas as instituições de ensino, como elucida Rita Maria de Souza Couto (2008), objetivando assegurar os conteúdos comuns, a flexibilidade e a qualidade da formação oferecida aos estudantes.

Dentre os aspectos apresentados pelo Parecer n $n^{\circ} 67$ (CNE/CES, 2003a), destaca-se a orientação de se construir um "modelo pedagógico capaz de adaptar-se à dinâmica das demandas da sociedade, em que a graduação passa a constituir-se numa etapa de formação inicial no processo contínuo da educação permanente". Nesse sentido, a referida autora destaca o dever das IES de incentivar uma sólida formação geral dos seus discentes, estimulando práticas de estudo independente que os possibilitem estabelecer uma progressiva autonomia profissional e intelectual. 
Para Rafael Cardoso (2012), a concepção popular de que um estudante, ao concluir a sua faculdade, seja um profissional "pronto", gera desnecessária ansiedade e frustração no jovem profissional. Segundo o autor, é papel da instituição de ensino promover aos alunos a reflexão de que para se tornar um bom profissional de qualquer área, inclui-se aqui o Design, é necessário um longo processo de aprendizagem, do qual a graduação é apenas uma etapa. As experiências advindas do trabalho, por meio da vivência em estágios e do exercício da prática profissional, somados ao continuo hábito de leituras, estudo e reflexão, são indispensáveis à construção de um bom profissional. "No mundo complexo, aprender a profissão é tarefa para toda a vida" (Cardoso, 2012, p. 239).

Auxiliando a formação do estudante, as IES devem fortalecer a articulação da teoria com a prática. É o que recomenda o Parecer $n^{\circ} 67$ (CNE/CES, 2003a): as instituições de ensino devem "contemplar orientações para as atividades de estágio e demais atividades que integrem o saber acadêmico à prática profissional, incentivando o reconhecimento de habilidades e competências adquiridas fora do ambiente escolar".

Versando sobre o ensino do Design, a CNE/CES elaborou o Parecer n ${ }^{\circ}$ 195, de 05 de agosto de 2003 (CNE/CES, 2003b), e a Resolução no 5, de 8 de março de 2004 (CNE/CES, 2004), estabelecendo as diretrizes curriculares dos cursos de graduação em Design, com o propósito de se definir uma abrangência desejável dos projetos pedagógicos, um perfil esperado dos egressos e os eixos de formação indispensáveis, e, ao mesmo tempo, permitir o atendimento, por parte das IES, das contínuas e emergentes mudanças do meio, da ciência e da tecnologia. Assim,

"o curso de graduação em Design deve ensejar, como perfil desejado do formando, capacitação para a apropriação do pensamento reflexivo e da sensibilidade artística, para que o designer seja apto a produzir projetos que envolvam sistemas de informações visuais, artísticas, estéticas, culturais e tecnólogicas, observados o ajustamento histórico, os traços culturais e de desenvolvimento das comunidades bem como as características dos usuários e de seu contexto sócio-econômico [sic] e cultural". (CNE/CES, 2003b; CNE/CES, 2004)

Também está definido no Parecer $n^{\circ} 195$ (CNE/CES, 2003b) e na Resolução ${ }^{\circ} 5$ (CNE/CES, 2004) as competências e habilidades mínimas esperadas dos egressos de cursos de graduação em Design no Brasil: a) a capacidade criativa, referente à proposição de soluções inovadoras a partir do domínio das técnicas de criação; b) o domínio da linguagem, que compreende a habilidade instrumental, técnica e expressiva para a comunicação de ideias, a partir do uso de diferentes mídias (escrita, fala e visual) e por meio de diversos recursos (manuais ou computacionais); c) o trânsito interdisciplinar, relacionado à capacidade de dialogar com diferentes áreas do conhecimento e a atuação em equipes multidisciplinares de desenvolvimento de pesquisa e de projeto; d) a visão 
sistêmica, que trata da capacidade de articular os diversos elementos materiais e imateriais do contexto projetual, como processos de fabricação, aspectos econômicos, psicológicos e sociológicos do produto; e) o domínio da metodologia projetual, referente à capacidade de trabalhar com fluidez entre as etapas que compreendem os métodos de desenvolvimento de projeto; f) o conhecimento do setor produtivo de sua especialização (visão setorial), relacionado ao mercado, materiais, processos produtivos e tecnologias abrangendo diversas manifestações regionais; g) a capacidade crítica para gerenciar projetos de Design, recursos humanos e processos produtivos; h) a visão histórica e prospectiva, centrada nos aspectos socioeconômicos e culturais, revelando consciência das implicações econômicas, sociais, antropológicas, ambientais, estéticas e éticas de sua atividade.

Em linhas gerais, a legislação brasileira contribui para avanços no campo do ensino do Design. Além disso, de acordo com Maria Rita de Souza Couto (2008), nas últimas décadas houve um esforço heroico de muitos docentes e pesquisadores no sentido de atualizar currículos de Design, introduzir novas disciplinas e promover discussões sobre questões da atualidade. De outro modo, por maior que seja o esforço empreendido por diversos docentes, ainda há certa resistência e dificuldade, de grande parte dos professores nos cursos de design no Brasil, para alinhar discurso e prática pedagógica, em resposta às complexas demandas da sociedade contemporânea.

Apesar da autonomia e da flexibilidade conferidas às instituições de ensino brasileiras, existe, ainda hoje, herança do processo de institucionalização do ensino do Design no país. Segundo Rafael Cardoso (2012), a grande maioria dos docentes que lecionaram nos primeiros cursos de Design do Brasil eram jovens e inexperientes, tanto como professores quanto como profissionais. Esse início caracterizado por um precário cunho pedagógico e pouca atenção às circunstâncias da vida econômica, social e cultural de então, contribuiu para uma cultura de, como denomina o autor, didatismo reativo, "obsessiva em seu apego às verdades recebidas, defensiva com relação a toda mudança, hostil a qualquer reflexão ou questionamento vindo de fora".

Às autonomia e flexibilidade conferidas às universidades brasileiras, de acordo com Maria Rita de Souza Couto (2008), soma-se a responsabilidade com a qual as instituições de ensino devem atuar. Seja em relação ao padrão de qualidade de seus cursos, que, indiscutivelmente, devem estar atrelados às transformações sociais, políticas, econômicas, culturais, científicas e tecnológicas, seja em cultivar, nos futuros profissionais, aptidões necessárias ao permanente e periódico ajustamento a essas mudanças. 


\section{Reflexões sobre o ensino do Design na atualidade}

Conforme apresentado anteriormente, percebe-se certo descompasso entre teoria, ensino e a prática do Design no Brasil. Tais dificuldades podem ser resultantes de um discurso ainda cambiante, em nosso território, sobre o conceito, a abrangência, os limites do Design, bem como a dimensão das habilidades e competências do profissional no desenvolvimento de projetos. Esse cenário aponta para a necessidade de alinhar o discurso sobre Design na academia, no exercício das práticas profissionais e na elaboração das políticas públicas para a melhoria da qualidade de vida.

A revisão periódica das práticas pedagógicas, pelo corpo docente dos cursos de Design, nas diversas IES, também é uma necessidade eminente. É preciso uma conscientização por parte dos docentes de que o projeto de Design para o futuro precisa acompanhar e, na maior parte das vezes, antever as mudanças no cenário social, econômico e político. Não é possível, em nossa realidade complexa, que as práticas voltadas ao ensino do projeto de Design na atualidade sejam uma repetição, acrítica, daquela apreendida pelo professor durante sua formação na graduação. Assim como na prática de projeto, no ensino do Design é necessário (re)pensar e (re)criar modelos didáticos, mais adequados às novas demandas sociais e individuais, e especialmente coerentes com o comportamento dessa nova geração de estudantes, sem contudo, lacerar os conhecimentos básicos essenciais e necessários à sua formação. Essa ação demanda tempo, dedicação e esforço coletivo, por parte do corpo docente nos cursos de formação de novos designers.

Sendo as IES caixas de ressonância das expectativas sociais, e sendo o professor um indispensável ator nesse processo, cabe, também a ele - e aqui não entramos no mérito das condições administrativas e econômicas das instituições de ensino - participar da construção do Plano Político Pedagógico da sua instituição e explorar, em suas aulas, as necessidades, possibilidades e cultura locais, a fim de contribuir para a formação de profissionais capazes de suprir as demandas de mercado e interferir nesta realidade por meio de práticas sociais condizentes.

Para Rafael Cardoso (2012), a complexidade presente no cotidiano das pessoas requer dos estudantes, docentes e pesquisadores, em especial os de Design, repensar conceitos e buscar respostas às novas demandas configuradas no cenário atual. Sem crítica e sem reflexão, quer como profissional ou como cidadão do mundo, as pessoas tendem a permanecer em posições secundárias em suas relações laborais e sociais, tornando-se percebidos mais como autômatos do que como autônomos. Nesse contexto, o pensamento sistêmico torna-se um valor associado à atuação do designer, cuja prática lhe incentiva construir habilidades para visualizar e compreender problemas pontuais e em rede, exercitar a criatividade e articular ideias para a proposição de solução assertiva. 
Pensar questões densas, relativas ao ser, estar e viver no mundo complexo, tais como a responsabilidade ambiental e a inclusão social, é tarefa inerente ao projeto de Design. Dada a importância desses, dentre outros "problemas" comumente evocados e experenciados no ensino do Design neste início do século XXI, pensando a melhoria da qualidade de vida das pessoas no mundo, devemos considerar que "projetar soluções para um mundo complexo passa por aceitar a complexidade como precondição em vez de combatê-la" (Cardoso, 2012, p. 230). Nesse cenário, a pesquisa faz parte do aprendizado do Design e se constitui como busca permanente de conhecimentos fora do campo em específico, ou seja, em outras áreas de interesse - das ciências exatas, humanas e biológicas, passando essencialmente pelas artes, ciências sociais e aplicadas. Essa atitude, quando tomada como prática permanente, contribui para fortalecer o repertório do estudante de Design, dando-lhe condições para questionar e sustentar as suas ações. (Cardoso, 2012)

De modo geral, a academia precisa se reciclar e se habituar ao trato transdisciplinar do Design. É consensual a ideia de que o Design seja um campo essencialmente híbrido, aberto ao diálogo com as mais variadas áreas do conhecimento. Isso porque se qualifica como um campo de inúmeras possibilidades na medida em que o entendemos como uma atividade de natureza projetual potencialmente transformadora, que atua no ajuste da materialidade aos modos e meios de vida dos indivíduos.

"Precisamos integrar ainda mais projeto e pesquisa, prática profissional e atividades culturais, sem perder de vista a natureza essencial do Design como atividade projetual, capaz de viabilizar soluções sistêmicas e criativas para os imensos desafios do mundo complexo. Queremos designers pensantes, sim; porém, não podemos nos dar ao luxo de formar designers que não sejam capazes de projetar. (...) Quanto mais o ensino souber se integrar a outras instâncias - mercado, indústria, meio cultural etc. - maiores as chances de se tornar um aprendizado verdadeiro, capaz de atuar em parceria com o campo profissional para formar os designers que todos queremos". (Cardoso, 2012, p. 253)

É consenso no contexto das IES, a utopia de que os processos educativos em Design dêem condições para que os estudantes identifiquem e qualifiquem adequadamente os desafios de projeto de sua competência, realizem o planejamento de maneira assertiva e proponham soluções inovadoras. Nesse intuito, podemos dizer que é essencial, no ensino do Design, que se invista na transdisciplinaridade para o desenvolvimento de visão sistêmica. Esse olhar permitirá que o designer consiga estabelecer laços de empatia com o outro. O fato de o estudante conseguir experimentar o mundo para o qual está projetando - ou seja, conhecer, viver, fazer parte e ser um pouco do outro - lhe auxiliará na atuação com competência em situações cotidianas ou inusitadas. 


\section{Relações entre o ensino do Design e a educação para o futuro: considerações finais}

Do nosso ponto de vista, as diretrizes educacionais brasileiras, as atinentes ao ensino do Design, estão alinhadas com as recomendações da UNESCO e com os sete saberes necessários à educação do futuro, apresentado por Edgar Morin (2011).

Toda a liberdade e a autonomia desejadas para o ensino do Design no Brasil propiciam condições favoráveis à educação para o futuro, conforme utopia apresentada na primeira parte deste estudo. É possível que nas IES brasileiras aconteça a formação de designers cidadãos do mundo, competentes para raciocinar sistematicamente em meio a uma realidade complexa, capazes, pois, de se situarem enquanto indivíduos pertencentes a uma comunidade, em seus diferentes níveis, de se entender e refletir sobre o seu papel enquanto agente de transformação local, parte de um contexto ampliado de território, e especialmente capazes de aprender, diariamente, a conviver, a conhecer, a fazer e a ser uma pessoa melhor para um mundo mais profícuo.

Dizendo de atitudes para facilitar ajustes no ensino do Design na realidade brasileira à ideia de ensino para o futuro, é preciso aproximar as práticas de projeto às questões locais e à existência humana, abarcar aspectos do cotidiano para os desafios projetuais.

De um modo geral, diante de uma avaliação generalizada e empírica sobre a realidade do ensino do Design no Brasil, considera-se necessário o alinhar do discurso e da ação dos docentes nesse campo. Nesse processo de ajuste é preciso assumir que os professores exercem papel fundamental para a mudança de atitude e implantação de uma nova mentalidade, mais de acordo com a realidade do século XXI.

Dada a velocidade e intensidade presentes em nosso cotidiano, há que se considerar que o futuro já chegou e, de um modo geral, os professores de Design demosntram certa insegurança para agir e morosidade para responder à urgência das mudanças necessárias para o ensino nesse novo tempo.

Um caminho para se alcançar tal objetivo seria a reflexão sobre os processos didáticos e pedagógicos adotados no ensino do Design, até então, utilizando, para isso, o método de pesquisa-ação. A partir da análise de suas práticas, os professores poderiam aprimorar o processo de ensino-aprendizado e potencializar o conhecimento e a formação dos estudantes de Design para o futuro e, como consequência, impulsionar sua própria atuação para a promoção da inovação científica, tecnológica e social no presente.

Acredita-se que, para efetivar o aprendizado do designer com vistas à sua atuação para o projeto de futuros desejáveis, é necessário que os professores estimulem os estudantes a partir de desafios reais, lhes permitindo reconhecimento com a realidade e a vivência de 
experiências que lhes instiguem ao aprendizado por toda a vida. A busca pelo conhecimento lhes dará oportunidade para o exercício do pensamento sistêmico, o exame das diversas variáveis da vida na atualidade, o raciocínio sobre os modos e meios de vida, a sugestão de trajetórias e possibilidades de solução, além da consciência ética e domínio de valores morais que lhes permita a tomada de decisão. De posse dessas competências, do nosso ponto de vista, o designer, agente transformador da realidade relacionada aos modos e meios de vida material para o futuro, estará habilitado a projetar produtos - em suas diversas vertentes - que respondam às diferentes demandas, e sejam capazes de promover a sensação de bem-estar na vida das pessoas.

É essencial que o designer aprenda a olhar o mundo, os lugares e as coisas pelo ponto de vista das pessoas que utilizarão produtos, processos e ou serviços projetados por ele. $\mathrm{O}$ Design, atividade de natureza projetual potencialmente transformador, precisa atuar no ajuste da materialidade aos modos e meios de vida dos indivíduos, em concordância com a realidade posta.

Enfim, implementando novas formas de pensar o projeto, a diversificação, o aprimoramento dos métodos e a possibilidade de ampliar o potencial das soluções em Design, é necessário que o professor, e por consequência o estudante, vislumbre novos caminhos para materializar futuros desejáveis. Acredita-se que, a partir de tais ações pelos professores, a atual geração de estudantes universitários responderá, sobremaneira, ao desafio posto, com novas e inovadoras ideias.

\section{Referências Bibliográficas}

BRASIL (1988). Constituição da República Federativa do Brasil de 1988. Brasília, DF, Senado, 1988.

BRASIL (1995). Lei $n^{\circ}$ 9.131, de 24 de novembro de 1995. Diário Oficial da União, Poder Executivo, Brasília, DF, 25 nov. 1995. Edição Extra. Seção 1, p. 19257. Altera dispositivos da Lei $\mathrm{n}^{\circ} 4.024$, de 20 de dezembro de 1961, e dá outras providências.

BRASIL (1996). Lei $\mathrm{n}^{\circ}$ 9.394, de 20 de dezembro de 1996. Diário Oficial da União, Poder Executivo, Brasília, DF, 23 dez. 1996. Seção 1, p. 27833. Estabelece as diretrizes e bases da educação nacional.

CARDOSO, Rafael. (2012). Design para um mundo complexo. São Paulo: Cosac Naify, 2012.

CNE/CES (2003a). Parecer n ${ }^{\circ}$ 67, de 11 de março de 2003. Diário Oficial da União, Brasília, DF, 02 jun. 2003, Seção 1, p. 7. Conselho Nacional de Educação e Câmara de Educação Superior: Referencial para as Diretrizes Curriculares Nacionais - DCN dos Cursos de Graduação. 
Cidaley de Oliveira Moreira, Samantha; Bom Conselho Sales, Rosemary; Barbosa, Paula Glória \& Aguilar, Maria Teresa Paulino.

CNE/CES (2003b). Parecer n ${ }^{\circ}$ 195, de 5 de agosto de 2003. Diário Oficial da União, Brasília, DF, 12 fev. 2004, Seção 1, p. 14. Conselho Nacional de Educação e Câmara de Educação Superior: Referencial para as Diretrizes Curriculares Nacionais - DCN dos Cursos de Graduação.

CNE/CES (2004). Resolução n ${ }^{\circ}$ 5, de 8 de março de 2004. Diário Oficial da União, Brasília, DF, 15 mar. 2004, Seção 1, p. 24. Conselho Nacional de Educação e Câmara de Educação Superior: Aprova as Diretrizes Curriculares Nacionais do Curso de Graduação em Design e dá outras providências.

COUTO, (2008) Rita Maria de Souza. Escritos sobre ensino de design no Brasil. Rio de Janeiro: Rio Book's,.

MORIN, Edgar. (2011). Os sete saberes necessários à educação do futuro. 2ed. São Paulo: Cortez; Brasília, DF: UNESCO.

UNESCO (1996). Educação. Um tesouro a descobrir. Relatório para a UNESCO da Comissão Internacional sobre educação para o século XXI. Jacques Delors (coord.). São Paulo: Cortez; Brasília, DF: UNESCO no Brasil. 